\title{
SISTEM PENENTUAN PEMBERIAN PINJAMAN DANA PADA KOPERASI SIMPAN PINJAM MENGGUNAKAN METODE SIMPLE ADDITIVE WEIGHTING
}

\author{
Gortap Lumbantoruan', Mufria J. Purba² \\ ${ }^{1,2}$ Universitas Methodist Indonesia \\ ${ }^{1}$ lumbantoruan.gortap@gmail.com,2jonatan.purba@gmail.com
}

\begin{abstract}
In providing loans, cooperatives have stages that must be passed before a credit is decided to be disbursed. The aim is to facilitate cooperatives in assessing the feasibility of a credit application. The loan eligibility assessment is carried out with many assessment criteria including employment, income, capital/shares, number of dependents and house status. Analysis of loan eligibility requires the accuracy of a credit analyst in analyzing credit applicants submitted by members. If the credit analysis is not precise, then the provision of credit funds can be difficult and even make a loss. So to determine whether a loan application can be accepted or not, of course the cooperative management has many multi-criteria considerations. In this study, an analysis was carried out using the Simple Additive Weighting method to facilitate the process of making feasibility decisions and eliminating lending to prospective debtors. The results of the study show that the results of the calculation of the determination of lending funds to members of savings and loan cooperatives using the simple additive weighting method can show alternatives that are eligible to receive loans with a preference value $>=60 \%$ and also alternatives that are not eligible to receive loans, namely with a preference value of $<=60 \%$. .
\end{abstract}

\section{Keywords: Cooperatives, Multicriteria, Loans, Simple Additive Weighting.}

\section{PENDAHULUAN}

Pemanfaatan teknologi informasi telah digunakan diberbagai bidang kehidupan atau aktivitas manusia, termasuk pada Koperasi Simpan Pinjam. Koperasi simpan pinjam adalah salah satu jenis koperasi yang ada di Indonesia yang mempunyai kegiatan utama adalah menyediakan jasa penyimpanan dan pinjaman dana kepada anggota koperasi dengan tujuan memajukan kesejahteraan anggota khususnya dan pada masyarakat pada umumnya [1].

Koperasi simpan pinjam menyediakan pinjaman atau kredit bagi masyarakat terutama golongan menengah kebawah. Dan koperasi pada umumnya, pinjaman atau kredit yang diberikan memiliki bunga yang rendah dan denda yang lebih ringan [2]. Dalam pemberian pinjaman, koperasi memiliki tahap-tahap yang harus dilalui sebelum suatu kredit diputuskan untuk dikucurkan. Tujuannya adalah untuk mempermudah koperasi dalam menilai kelayakan suatu permohonan kredit. Dalam proses bisnis koperasi, pemberian kredit kepada peminjam mengandung beberapa unsur yaitu kepercayaan, kesepakatan, jangka waktu, resiko serta mendapatkan keuntungan berupa bunga [3].

Sesuai dengan tujuan koperasi simpan pinjam yaitu untuk membantu memajukan masyarakat, banyak pemohon kredit yang mengajukan kredit dengan kondisi ekonomi yang berbeda-beda. Penilaian kelayakan pinjaman dilakukan dengan banyak kriteria penilaian. Penilaian kelayakan pinjaman dituntut ketelitian seorang analis kredit dalam menganalisis pemohon kredit yang diajukan anggota. Jika analisa kredit kurang tepat, maka pemberian dana kredit tersebut dapat menyulitkan dan bahkan membuat rugi. Maka untuk menentukan sebuah ajuan pinjaman dapat diterima atau tidak, tentu pihak koperasi memiliki banyak pertimbangan [4].
Untuk mengurangi atau menghilangkan kesalahan dalam analisis kelayakan anggota dalam melakukan pinjaman, maka perlu mengikuti perkembangan teknologi informasi dengan membuat suatu sistem pendukung keputusan yang dapat menunjang kinerja dalam analisis pinjaman [5]. Adanya Sistem Pendukung Keputusan ini dapat mempermudah proses pengambilan keputusan pemberian pinjaman kepada calon debitur, dan dapat mendukung dalam pengambilan keputusan mengenai layak atau tidaknya anggota koperasi untuk diberikan pinjaman [6].

\section{TINJAUAN PUSTAKA}

\section{Pinjaman}

Kredit dari asal-usul katanya berasal dari kata credere, yang artinya kepercayaan. Kepercayaan yang dimaksud di dalam perkreditan adalah antara si pemberi kredit. Kredit juga berarti memperoleh barang dengan membayar cicilan atau angsuran di kemudian hari atau memperoleh pinjaman uang yang pembayarannya dilakukan di kemudian hari dengan cicilan atau angsuran sesuai dengan perjanjian [2]. Prosedur pemberian pinjaman antara instansi keuangan dengan yang lainnya secara umum tidak jauh berbeda, prosedurnya memiliki tahap-tahap yang harus dilalui sebelum suatu kredit diputuskan untuk dikucurkan. [7].

Unsur-unsur pemberian kredit oleh jasa keuangan kepada peminjam mengandung beberapa unsur,yaitu [3] 1. Kepercayaan

Keyakinan pemberi kredit bahwa kredit yang diberikan (baik berupa uang, barang atau jasa) akan benar-benar diterima kembali di masa yang akan datang sesuai jangka waktu kredit.

2. Kesepakatan

Kesepakatan antara si pemberi kredit dengan si penerima kredit yang dituangkan dalam suatu 
perjanjian di mana masing-masing pihak menandatangani hak dan kewajibannya masingmasing.

3. Jangka waktu

Masa pengembalian kredit yang telah disepakati bersama.jangka waktu tersebut dapat berupa jangka waktu yang pendek, menegah ataupun jangka panjang.

4. Risiko

Adanya suatu tenggang waktu pengembalian akan menyebabkan suatu risiko tidak tertagihnya/macet pemberian kredit.

5. Balas jasa

Keuntungan atas pemberian suatu kredit atau pembiayaan yang dikenal sebagai bunga atau bagi hasil.

\section{Simple Additive Weighting}

Metode Simple Additive Weighting (SAW) sering juga dikenal dengan istilah metode penjumlahan terbobot dimana setiap alternatif memiliki bobot sesuai kriteria yang telah ditentukan pengambil keputusan. Konsep dasar metode SAW adalah menjumlahkan bobot-bobot dari setiap alternatif hingga menghasilkan rating kinerja untuk setiap kriteria atau atribut. Kriteria yang digunakan dalam metode SAW memiliki 2 sifat yaitu kriteria keuntungan (benefit) dan kriteria biaya (cost). Kriteria keuntungan (benefit) digunakan jika nilai bobot yang terbesar adalah yang terbaik, sedangkan kriteria biaya (cost) digunakan jika nilai bobot yang terkecil adalah yang terbaik.

Pemilihan sifat kriteria ini tergantung pada permasalahan yang dihadapi yang kadang kala alternatif keputusan dengan nilai terkecil adalah keputusan yang terbaik atau alternatif dengan nilai yang terbesar adalah keputusan yang terbaik. Dalam menentukan keputusan yang terbaik berdasarkan kriteria benefit ataupun kriteria cost, metode SAW membutuhkan proses normalisasi matriks keputusan (X) ke suatu skala yang dapat diperbandingkan dengan semua rating alternatif yang ada hingga menghasilkan perangkingan alternatif keputusan yang dapat diambil pengambil keputusan [4].

\section{METODE PENELITIAN}

\section{Alur Penelitian}

Langkah-langkah penyelesaian masalah pemberian pinjaman dengan metode SAW dapat dilihat seperti flowchart berikut ini:

1. Menentukan kriteria yang akan dijadikan acuan dalam menentukan pengambilan keputusan.

2. Memberikan nilai setiap alternatif pada setiap kriteria yang sudah ditentukan

3. Menentukan rating kecocokan setiap alternatif pada setiap kriteria

4. Matriks Keputusan Berdasarkan Kriteria

5. Melakukan Normalisasi matriks $\mathrm{X}$ menjadi matriks R

6. Menghasilkan Nilai Preferensi

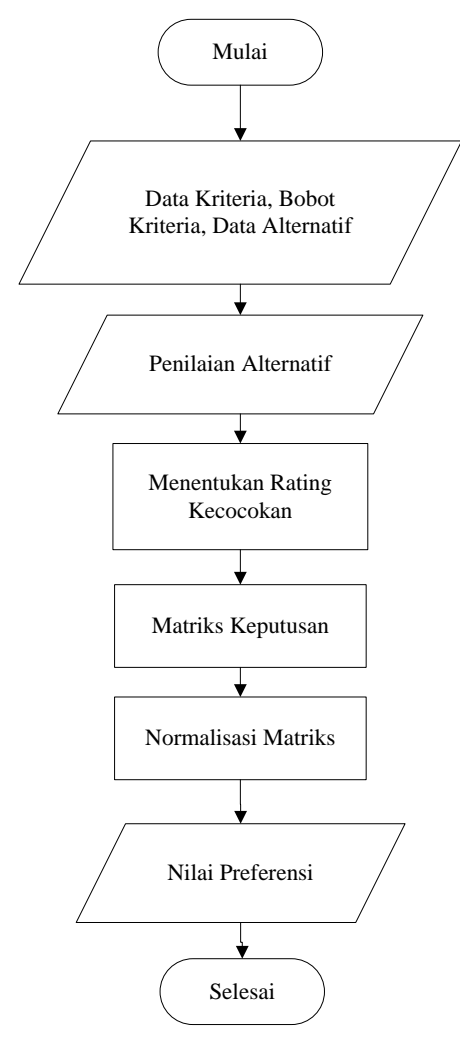

Gambar1. Alur Penelitian

\section{Pengumpulan Data}

Data yang digunakan dan diolah dalam penelitian ini diperoleh dari studi kepustakaan dari berbagai berbagai karya ilmiah yang berhubungan dengan penelitian dan disesuaikan dengan kebutuhan. Studi kepustakaan merupakan serangkaian kegiatan yang berkenaan dengan metode pengumpulan data pustaka, membaca dan mencatat serta mengolah bahan penelitian [8]. Pengumpulan informasi dan data dapat dilakukan dengan bantuan berbagai macam material seperti buku referensi, hasil penelitian sebelumnya yang sejenis, artikel, catatan, serta berbagai jurnal yang berkaitan dengan masalah yang ingin dipecahkan [9].

\section{Kriteria}

Adapun kriteria yang digunakan dalam sistem pendukung keputusan dengan metode simple additive weighting adalah dengan menentukan kriteria penilaian seperti yang terdapat pada tabel 1. Bobot seluruh kriteria memiliki total $100 \%$ dimana masingmasing kriteria akan diberi bobot sesuai tingkat kepentingan kriteria tersebut terhadap penentuan pemberian pinjaman dana.

\begin{tabular}{|r|l|l|}
\multicolumn{3}{|l}{ Tabel 1. Kriteria Penilaian } \\
\hline Kode & Kriteria & Bobot \\
\hline C1 & Pekerjaan & 20 \\
\hline C2 & Penghasilan & 25 \\
\hline C3 & Modal & 25 \\
\hline C4 & Jumlah Tanggungan & 10 \\
\hline C5 & Status Rumah & 20 \\
\hline
\end{tabular}

Sedangkan ketentuan layak tidaknya seorang anggota 
koperasi dalam melakukan pinjaman dana adalah sebagai berikut:

- Jika nilai preferensi $\mathrm{V} \geq \mathbf{6 0 \%}$ maka anggota layak mendapat pinjaman

- Jika nilai preferensi $\mathbf{V} \leq \mathbf{6 0} \%$ maka anggota tidak layak mendapat pinjaman

Setiap kriteria seperti yang tertera pada tabel 3.2 diatas, akan diberi tingkatan himpunan kriteria serta bobot sesuai dengan tingkat kepentingan himpunan kriteria seperti dijelaskan berikut ini:

a. Pekerjaan $\left(\mathrm{C}_{1}\right)$

Tabel 2. Kriteria Pekerjaan

\begin{tabular}{|l|l|l|}
\hline Kriteria & Himpunan Kriteria & Bobot \\
\hline \multirow{4}{*}{ Pekerjaan } & Petani & 1 \\
\cline { 2 - 3 } & KaryawanSwasta & 2 \\
\cline { 2 - 3 } & Pedagang & 3 \\
\cline { 2 - 3 } & PNS & 4 \\
\hline
\end{tabular}

b. Penghasilan $\left(\mathrm{C}_{2}\right)$

Tabel 3. Kriteria Penghasilan

\begin{tabular}{|l|l|l|}
\hline Kriteria & Himpunan Kriteria & Bobot \\
\hline \multirow{4}{*}{ Penghasilan } & $<1,5$ juta & 1 \\
\cline { 2 - 3 } & $1,5-2$ juta & 2 \\
\cline { 2 - 3 } & 3 juta -5 juta & 3 \\
\cline { 2 - 3 } & $>5$ juta & 4 \\
\hline
\end{tabular}

c. Modal $\left(\mathrm{C}_{3}\right)$

Tabel 4. Kriteria Modal

\begin{tabular}{|l|l|l|}
\hline Kriteria & Himpunan Kriteria & Bobot \\
\hline \multirow{4}{*}{ Modal } & $500.000-1.000 .000$ & 1 \\
\cline { 2 - 3 } & $1.500 .000-2.000 .000$ & 2 \\
\cline { 2 - 3 } & $2.500 .000-5.000 .000$ & 3 \\
\cline { 2 - 3 } & $>5.000 .000$ & 4 \\
\hline
\end{tabular}

d. Jumlah Tanggungan $\left(\mathrm{C}_{4}\right)$

Tabel 5. Kriteria Tanggungan

\begin{tabular}{|l|l|l|}
\hline Kriteria & Himpunan Kriteria & Bobot \\
\hline \multirow{4}{*}{ Jumlah } & $>7$ Orang & 1 \\
\cline { 2 - 3 } Tanggungan & $6-5$ Orang & 2 \\
\cline { 2 - 3 } & $4-3$ Orang & 3 \\
\cline { 2 - 3 } & $<3$ Orang & 4 \\
\hline
\end{tabular}

e. Status Rumah $\left(\mathrm{C}_{5}\right)$

Tabel 6. Kriteria Status Rumah

\begin{tabular}{|l|l|l|}
\hline Kriteria & Himpunan Kriteria & Bobot \\
\hline \multirow{4}{*}{ Status Rumah } & Kontrak & 1 \\
\cline { 2 - 3 } & KPR & 2 \\
\cline { 2 - 3 } & Milik Orang tua & 3 \\
\cline { 2 - 3 } & Milik Sendiri & 4 \\
\hline
\end{tabular}

\section{HASIL DAN PEMBAHASAN}

\section{Memberikan Nilai Setiap Alternatif}

Setiap anggota yang ingin melakukan peminjaman disebut sebagai alternatif. Setiap alternatif akan diberi nilai untuk setiap kriteria sesuai dengan kondisi masing-masing alternatif untuk selanjutnya dianalisis kelayakan peminjaman dana.
Tabel 7. Data Nilai Alternatif

\begin{tabular}{|c|l|l|l|l|l|}
\hline \multirow{2}{*}{ Kode } & \multicolumn{5}{|c|}{ Kriteria } \\
\cline { 2 - 6 } & \multicolumn{1}{|c|}{$\mathbf{C}_{\mathbf{1}}$} & $\mathbf{C}_{\mathbf{2}}$ & \multicolumn{1}{c|}{$\mathbf{C}_{\mathbf{3}}$} & $\mathbf{C}_{\mathbf{4}}$ & \multicolumn{1}{c|}{$\mathbf{C}_{\mathbf{5}}$} \\
\hline A1 & Petani & 3 juta & 600.000 & 3 & Milik Sendiri \\
\hline A2 & $\begin{array}{l}\text { Karyawan } \\
\text { Swasta }\end{array}$ & 2 juta & 500.000 & 2 & Orang tua \\
\hline A3 & PNS & 5 juta & 1.000 .000 & 4 & KPR \\
\hline A4 & Pedagang & 5.5 juta & 1.500 .000 & 4 & Milik Sendiri \\
\hline A5 & Pedagang & 2 Juta & 500.000 & 4 & KPR \\
\hline
\end{tabular}

\section{Menentukan rating kecocokan}

Berdasarkan data di atas, maka dihasilkan rating kecocokan dari setiap alternatif untuk setiap kriteria yang dikonversikan dengan bobot berdasarkan himpunan kriteria, seperti tabel berikut:

Tabel 8. Rating Kecocokan

\begin{tabular}{|c|c|c|c|c|c|}
\hline Alternatif & $\mathrm{C}_{1}$ & $\mathrm{C}_{2}$ & $\mathrm{C}_{3}$ & $\mathrm{C}_{4}$ & $\mathrm{C}_{5}$ \\
\hline $\mathrm{A} 1$ & 1 & 3 & 1 & 3 & 4 \\
\hline $\mathrm{A} 2$ & 2 & 2 & 1 & 4 & 3 \\
\hline $\mathrm{A} 3$ & 4 & 3 & 1 & 3 & 2 \\
\hline $\mathrm{A} 4$ & 3 & 4 & 2 & 3 & 4 \\
\hline A5 & 3 & 2 & 1 & 3 & 2 \\
\hline
\end{tabular}

Matriks Keputusan Berdasarkan Kriteria.

Dari tabel rating kecocokan alternatif diatas akan diubah kedalam matriks keputusan X seperti berikut:

$$
X=\left\{\begin{array}{lllll}
1 & 3 & 1 & 3 & 4 \\
2 & 2 & 1 & 4 & 3 \\
4 & 3 & 1 & 3 & 2 \\
3 & 4 & 2 & 3 & 4 \\
3 & 2 & 1 & 3 & 2
\end{array}\right\}
$$

\section{Melakukan Normalisasi Matriks}

Normalisasi matriks X menjadi matriks R dapat dilihat seperti perhitungan berikut ini:

a. Kriteria Kualitas Kerja (K1).

$$
\begin{aligned}
& \mathrm{r} 1,1=\frac{1}{\operatorname{Max}\{1,2,4,3,3\}}=\frac{1}{4}=0,25 \\
& \mathrm{r} 2,1=\frac{2}{\operatorname{Max}\{1,2,4,3,3\}}=\frac{2}{4}=0,5 \\
& \mathrm{r} 3,1=\frac{4}{\operatorname{Max}\{1,2,4,3,3\}}=\frac{4}{4}=1 \\
& \mathrm{r} 4,1=\frac{3}{\operatorname{Max}\{1,2,4,3,3\}}=\frac{3}{4}=0,75 \\
& \mathrm{r} 5,1=\frac{3}{\operatorname{Max}\{1,2,4,3,3\}}=\frac{3}{4}=0,75
\end{aligned}
$$

b. Kriteria Kerjasama (K2).

$$
\begin{aligned}
& r 1,2=\frac{3}{\operatorname{Max}\{3,2,3,4,2\}}=\frac{3}{4}=0,75 \\
& r 2,2=\frac{2}{\operatorname{Max}\{3,2,3,4,2\}}=\frac{2}{4}=0,5 \\
& r 3,2=\frac{3}{\operatorname{Max}\{3,2,3,4,2\}}=\frac{3}{4}=0,75 \\
& r 42=\frac{4}{\operatorname{Max}\{3,2,3,4,2\}}=\frac{4}{4}=1 \\
& r 5,2=\frac{2}{\operatorname{Max}\{3,2,3,4,2\}}=\frac{2}{4}=0,5
\end{aligned}
$$


c. Kriteria Pelayanan (K3).

$$
\begin{aligned}
& r 1,3=\frac{1}{\operatorname{Max}\{1,1,1,2,1\}}=\frac{1}{2}=0,5 \\
& r 2,3=\frac{1}{\operatorname{Max}\{1,1,1,2,1\}}=\frac{1}{2}=0.5 \\
& r 3,3=\frac{1}{\operatorname{Max}\{1,1,1,2,1\}}=\frac{1}{2}=0,5 \\
& r 4,3=\frac{2}{\operatorname{Max}\{1,1,1,2,1\}}=\frac{2}{2}=1 \\
& r 5,3=\frac{1}{\operatorname{Max}\{1,1,1,2,1\}}=\frac{1}{2}=0,5
\end{aligned}
$$

d. Kriteria Integritas (K4).

$$
\begin{aligned}
& r 1,4=\frac{3}{\operatorname{Max}\{3,4,3,3,3\}}=\frac{3}{4}=0,75 \\
& r 2,4=\frac{4}{\operatorname{Max}\{3,4,3,3,3\}}=\frac{4}{4}=1 \\
& r 3,4=\frac{3}{\operatorname{Max}\{3,4,3,3,3\}}=\frac{3}{4}=0,75 \\
& r 4,4=\frac{3}{\operatorname{Max}\{3,4,3,3,3\}}=\frac{3}{4}=0,75 \\
& r 5,4=\frac{3}{\operatorname{Max}\{3,4,3,3,3\}}=\frac{3}{4}=0.75
\end{aligned}
$$

e. Kriteria Disiplin (K5).

$$
\begin{aligned}
& r 1,5=\frac{4}{\operatorname{Max}\{4,3,2,4,2\}}=\frac{4}{4}=1 \\
& r 2,5=\frac{3}{\operatorname{Max}\{4,3,2,4,2\}}=\frac{3}{4}=0,75 \\
& r 3,5=\frac{2}{\operatorname{Max}\{4,3,2,4,2\}}=\frac{2}{4}=0,5 \\
& r 4,5=\frac{4}{\operatorname{Max}\{4,3,2,4,2\}}=\frac{4}{4}=1 \\
& r 5,5=\frac{2}{\operatorname{Max}\{4,3,2,4,2\}}=\frac{2}{4}=0,5
\end{aligned}
$$

Kemudian dari perhitungan diatas didapatkan nilai matriks normalisasi, nilai tersebut akan dibuat kedalam matriks normalisasi. Berikut ini merupakan hasil perhitungan matriks ternormalisasi:

$$
\mathrm{R}=\left\{\begin{array}{ccccc}
0,25 & 0,75 & 0,5 & 0,75 & 1 \\
0,5 & 0,5 & 0,5 & 1 & 0,75 \\
1 & 0,75 & 0,5 & 0,75 & 0,5 \\
0,75 & 1 & 1 & 0,75 & 1 \\
0,75 & 0,5 & 0,5 & 0,75 & 0,5
\end{array}\right\}
$$

\section{Nilai Preferensi}

Selanjutnya akan dicari nilai preferensi dengan perkalian matriks $\mathrm{W} * \mathrm{R}$ dimana Nilai $\mathrm{W}$ merupakan persentasi nilai bobot setiap kriteria penilaian yang ditentukan yaitu $(\mathrm{C}=20, \mathrm{C} 2=25, \mathrm{C} 3=25, \mathrm{C} 4=10$, $\mathrm{C5}=20$ ). Maka proses perangkingan diperoleh berdasarkan persamaan diatas sebagai berikut :

$$
\begin{aligned}
& \mathrm{V}_{1}=(0,25)(20)+(0,75)(25)+(0,5)(25)+(0,75)(10) \\
& +(1)(20)=63.75 \\
& \mathrm{~V}_{2}=(0,5)(20)+(0,5)(25)+(0.5)(25)+(1)(10)+ \\
& (0,75)(20)=60 \\
& \mathrm{~V}_{3}=(1)(20)+(0.75)(25)+(0,5)(25)+(0.75)(10)+ \\
& (0,5)(20)=68.75 \\
& \mathrm{~V}_{4}=(0,75)(20)+(1)(25)+(1)(25)+(0,75)(10)+
\end{aligned}
$$

$$
\begin{aligned}
& (1)(20)=92.5 \\
& V_{5}=(0.75)(20)+(0,5)(25)+(0,5)(25)+(0.75)(10) \\
& +(0,5)(20)=57.5
\end{aligned}
$$

Berdasarkan hasil perhitungan diatas, maka didapat nilai preferensi seperti berikut ini:

Tabel 9. Kelayakan Pengajuan Pinjaman

\begin{tabular}{|c|c|c|c|}
\hline Alternatif & Nilai & Nilai $(\%)$ & Kelayakan \\
\hline A1 & 63,75 & 63,75 & Layak \\
\hline A2 & 60 & 60 & Layak \\
\hline A3 & 68,75 & 68,75 & Layak \\
\hline A4 & 92,5 & 92,5 & Layak \\
\hline A5 & 57,5 & 57,5 & Tidak Layak \\
\hline
\end{tabular}

Maka dapat disimpulkan dari hasil perhitungan penentuan pemberian pinjaman dana pada nasabah koperasi simpan pinjam menggunakan metode simple additive weighting adalah alternatif A1, A2, A3 dan A5 layak mendapatkan pinjaman dari koperasi karena nilai preferensi $>=60 \%$. Sedangkan alternatif A4 tidak layak mendapatkan pinjaman karena memiliki nilai preferensi $<=60 \%$.

\section{KESIMPULAN}

Berdasarkan penelitian yang dilakukan oleh peneliti, maka dapat disimpulkan beberapa hal seperti sistem pendukung keputusan dapat menentukan pemberian pinjaman dana pada nasabah koperasi simpan pinjam dan membantu pihak pimpinan koperasi dalam menentukan anggota yang layak menerima pinjaman dana. Penentuan pemberian pinjaman dana pada nasabah koperasi simpan pinjam berhasil diterapkan dengan metode Simple Additive Weighting kedalam sistem. Nilai bobot setiap kriteria memiliki pengaruh terhadap nilai yang dihasilkan dan menghasilkan keputusan yang berbeda. Dengan adanya pendukung keputusan maka penentuan pemberian pinjaman dana pada nasabah koperasi simpan pinjam dapat lebih berkualitas dan efektif.

\section{REFERENSI}

[1] H. Nurdiyanto and S. Y. Minarto, "Pada Koperasi Serba Usaha Berkah Tiram Jaya Menggunakan Metode Analytic Hierarchy Process ( Ahp )," Tek. Inform., no. November 2016, 2018.

[2] T. Wahyono and A. D. Cahyono, "Analisis Desain Sistem Pendukung Keputusan Permohonan Kredit Dengan Penerapan Analisa Kredit Berbasis 5C Dan Pendekatan Komputasional," Fak. Teknol. Inf. Univ. Kristen Satya Wacana, pp. 1-7, 2014.

[3] D. Silly, A. Kristi, M. Saifi, and Dwiatmanto, "Evaluasi Sistem Dan Prosedur Pemberian Kredit Mikro Dalam Rangka Mendukung Pengendalian Intern ( Studi pada PT . Bank Jatim Cabang Utama Kediri )," J. Adm. Bisnis, vol. 55, no. 1, pp. 170-179, 2018.

[4] Timotius, F. Agus Setyaningsih, and U. Ristian, "Sistem Pendukung Keputusan Peminjaman Dana Kredit CU BIMA Cabang Tempunak Menggunakan 
Metode Simple Addictive Weighting (SAW) Berbasis Web," J. Coding, vol. 06, no. 03, pp. 265275,2018

[5] Ivandari, T. T. Chasanah, and M. A. Al Karomi, "Sistem Pendukung Keputusan Persetujuan Kredit dengan Pemanfaatan Information Gain untuk Pembobotan Atribut Klasifikasi K-Nearest Neighbour," IC-Tech, vol. 12, no. 2, pp. 14-19, 2017.

[6] S. Anjarwati and E. H. Kuncoro, "Sistem Pendukung Keputusan Pemberian Pinjaman Pada Koperasi Unit Desa ( KUD ) Menggunakan The Satisficing Model," J. VOI STMIK Tasikmalaya, vol. 5, no. 1, pp. 46-54, 2016.

[7] N. Sri Wulandari, "Analisis Faktor-Faktor yang Mempengaruhi Pengambilan Keputusan Dalam Melakukan Pinjaman Pada Koperasi Simpan Pinjam 'Artha Jaya Mandiri Cabang Ponorogo,"” Universitas Muhammadiyah Ponorogo, 2018.

[8] Supriyadi, "Community of Practitioners: Solusi Alternatif Berbagi Pengetahuan antar Pustakawan," Lentera Pustaka J. Kaji. Ilmu Perpustakaan, Inf. dan Kearsipan, vol. 2, no. 2, p. 83, 2016, doi: 10.14710/lenpust.v2i2.13476.

[9] M. Sari and Asmendri, "Penelitian Kepustakaan (Library Research) dalam Penelitian Pendidikan IPA," Nat. Sci., vol. 2, no. 1, p. 15, 2018. 